\title{
Downregulation of RPN2 induces apoptosis and inhibits migration and invasion in colon carcinoma
}

\author{
CHONGYAO BI ${ }^{1}$ and BAOFEI JIANG ${ }^{2}$ \\ ${ }^{1}$ Department of General Surgery, Jiaozhou Central Hospital of Qingdao, Qingdao, Shandong 266300; \\ ${ }^{2}$ Department of General Surgery, Huai'an First People's Hospital, Nanjing Medical University, \\ Huai'an, Jiangsu 223300, P.R. China
}

Received October 31, 2017; Accepted April 27, 2018

DOI: $10.3892 /$ or.2018.6434

\begin{abstract}
The morbidity of colorectal cancer (CRC) increases annualy, which accounts to higher mortality worldwide. Therefore, it is important to study the pathogenesis of colon cancer. Ribophorin II (RPN2), part of the $\mathrm{N}$-oligosaccharyltransferase complex, is highly expressed in CRC. In the present study, we investigated whether RPN2 can regulate apoptosis, migration and invasion by RNA interference in CRC and sought to clarify the molecular mechanism involved. Based on previous research, an abnormal high expression of RPN2 was observed in CRC tissues and cell lines by real-time (RT)-PCR, immunohistochemistry (IHC) and western blot analysis. RPN2 knockdown via small RNA interference (siRNA) strategy attenuated the expression of RPN2 at the mRNA and protein levels in vivo, leading to decreased cell viability and increased cell apoptosis. In addition, RNAi-RPN2 effectively arrested the cell cycle at the G0/G1-phase in SW1116 and SW480 cells. Furthermore, the Transwell assay demonstrated that cell migration and invasion abilities were significantly inhibited after cell transfection with RPN2 interference plasmid. The apoptosis-related protein (caspase-3) expression was increased and the cell cycle-related protein (cyclin D1) expression was decreased in the siRNA-RPN2 group. RT-PCR and western blot analysis results indicated that migration- and invasion-related proteins including E-cadherin, matrix metalloproteinases (MMP)-2 and TIMP-2 were markedly regulated by RPN2 siRNA. Phosphorylation levels of signal transducer and activator of transcription (STAT)3 and Janus kinase (JAK)2 were inhibited by RPN2 siRNA. These findings indicated a novel pathway of tumor-promoting activity by RPN2 in CRC, with significant implications for unraveling the tumorigenesis of CRC.
\end{abstract}

Correspondence to: Dr Baofei Jiang, Department of General Surgery, Huai'an First People's Hospital, Nanjing Medical University, 6 Beijing Road West, Huai'an, Jiangsu 223300, P.R. China

E-mail: bjjiang_ha@163.com

Key words: RPN2, apoptosis, migration, invasion, JAK2/STAT3, colon carcinoma

\section{Introduction}

Colorectal cancer (CRC) is the most common gastrointestinal tumor malignancy (1). With the rapid speed of our country's aging process, the incidence rate of CRC shows an upward trend (2). At present, the causes of CRC are considered the result of external environmental factors combined with internal organism factors. Unhealthy lifestyle, anti-oncogene inactivation and oncogene mutations can cause cells to grow uncontrollably, and further lead preexisting diseases such as ulcerative colitis and colonic adenoma to develop into malignant tumor (3-6). Research has demonstrated that most patients die from tumor metastasis and recurrence (7). The essential characteristics of malignant tumors are excessive proliferation, differentiation failure and apoptosis disorder (8). Therefore, it is important to explore the mechanisms of tumor growth, metastasis and recurrence in CRC. Ribophorin II (RPN2) is a membrane glycoprotein which is found in rough endoplasmic reticulum, located at chromosome 20q12-13.1 and has glycosylation function affecting protein stability and secretion and play a key role in cell function and signal transduction $(9,10)$. Research has indicated that RPN2 was highly expressed in tumor stem cells (11). RPN2 promoted cellular malignant proliferation in breast cancer by regulating $\mathrm{N}$-glycosylation of CD36 (12). In addition, RPN2 interference reduced the glycosylation of P-glycoprotein to promote docetaxel-dependent apoptosis in esophageal squamous cell carcinoma (ESCC) (13). In osteosarcoma and gastric carcinoma, studies have revealed that the expression of RPN2 was closely associated with patient survival time and tumor stage $(14,15)$. It was also reported that RPN2 was highly expressed in CRC (16). Therefore, we hypothesized that RPN2 plays an important role in the development and progression of CRC.

Signal transducer and activator of transcription (STAT)3 belongs to the transcription factor family. STAT3 monomer, is expressed in the cytoplasm (17). Research has indicated that STAT3 was persistently activated in $50 \%$ of lung cancers (18). In addition, Janus kinase (JAK)2, as a key factor in the process of STAT3 phosphorylation, can be bound to the membrane receptor and trigger tyrosine receptor to activate STAT3 (19). STAT3-mediated target genes play an important role in the occurrence and development of the tumor, including migration, invasion and angiogenesis $(20,21)$. In CRC, the activation 
of STAT3/JAK2 signaling pathway can promote epithelialmesenchymal transition (EMT) and enhance the abilities of migration and invasion in many types of cancer (22). Therefore, we hypothesized that the STAT3/JAK2 signaling pathway regulated the expression level of related proteins to affect the development of CRC with the action of RPN2.

\section{Materials and methods}

Patients and tissue samples. A total of 43 samples of CRC tissues and benign tissues surgically removed from patients in Huai'an First People's Hospital were collected from March 2014 to December 2017. Preoperative clinical and pathological follow-up data were completed by all patients. Ethical approval for the study was provided by the Ethics Committee of Huai'an First People's Hospital. Written informed consent was obtained from all the study participants.

Immunohistochemistry. Tissue sections were initially treated with deparaffinization and hydration and then heated in EDTA ( $\mathrm{pH} \mathrm{8.0)}$ and antigen-retrieved in $10-\mathrm{mm}$ citrate buffer for $5 \mathrm{~min}$ at $100^{\circ} \mathrm{C}$. The reaction of RPN2 antibody (dilution 1:500; cat. no. ab64467; Abcam, Cambridge, MA, USA) took place for $1 \mathrm{~h}$ at room temperature, and then incubation followed by biotin-labeled secondary antibodies (1:500; cat. no. PL0306214; PLlabs, Toronto, Canada) and slides developed using DAB solution and counterstained with hematoxylin staining (Baso Diagnostic, Inc., Wuhan, China). Immunohistochemical signals were calculated with the positive staining cells under a light microscope (Olympus Corporation, Tokyo Japan) at a magnification of x200.

Cell culture. Human colon epithelial NCM460 cells were obtained from the Cell Engineering Research Center of The Fourth Military Medical University (Xi'an, China) and were cultured in RPMI-1640 medium (Gibco; Thermo Fisher Scientific, Inc., Waltham, MA, USA) containing $10 \%$ fetal bovine serum (FBS), $10 \mathrm{ng} / \mathrm{ml}$ epidermal growth factor (EGF) (both from Invitrogen; Thermo Fisher Scientifc, Inc.), 1\% insulin (First Biological and Chemical Medication, Co., Ltd., Shanghai, China), $5 \mu \mathrm{g} / \mathrm{ml}$ hydrocortisone (The Third Pharmaceutical, Co., Beijing, China) and $1 \%$ penicillin/streptomycin at $37^{\circ} \mathrm{C}$ in a humidified atmosphere of $5 \% \mathrm{CO}_{2}$. Human colon cancer cell lines (SW1116, SW480, LoVo, SW403 and SW620) were purchased from SUER Bio-Technique, Co., Ltd. ( Shanghai, China) and cultured in Dulbecco's modified Eagle's medium (DMEM; Sigma-Aldrich; Merck KGaA, Darmstadt, Germany) containing 10\% FBS and 1\% penicillin/streptomycin at $37^{\circ} \mathrm{C}$ in a humidified atmosphere of $5 \% \mathrm{CO} 2$.

siRNA transfection. SW1116 and SW480 cells were seeded onto 6-well culture plates at a density of $3 \times 10^{5}$ cells/well. The RPN2 siRNA or control siRNA, were both purchased from Shanghai GenePharma, Co., Ltd., (Shanghai, China) and were transfected into cells at 50-60\% confluency using Lipofectamine ${ }^{\mathrm{TM}} 2000$ (Invitrogen, Shanghai, China) following the manufacturer's protocol. After $48 \mathrm{~h}$, the transfected cells were collected and processed for the subsequent experiments. The sequence of RPN2 siRNA used was: forward, 5'-CCTAGAGGTACCGG AATGCGTTAAGCTATACCTGCATTGGCTAGTTAACGT
AGAACCG-3' and reverse, 5'-CCTACGTTAAGCAATTCA ATTTTTTGTATAGCTTAACTACCGCATTTCGAGGTAG TAG-3'. The sequence of the negative (mock) siRNA used was 5'-ACGCCUCCCGAACGUTTUUCUUGUCGUC-3'.

CCK- 8 assay. Cell viability was evaluated using cell counting kit-8 (CCK-8) assay. In brief, after $48 \mathrm{~h}$ of transfection, SW1116 and SW480 cells were seeded at a density of $4 \times 10^{3}$ cells/well in 96-well plates and incubated for 0, 12, 24, 48 and $72 \mathrm{~h}$. Subsequently, $20 \mu 1$ of CCK- 8 was added to each well for another 1-h incubation. The optical density (OD) values were determined at $450 \mathrm{~nm}$ using a microplate reader (Thermo Fisher Scientific, Inc.). All experiment concentrations were assessed in triplicate.

Cell cycle analysis. Flow cytometry was used for the analysis of the cell cycle. After 48-h transfection, cells were harvested and then fixed in ice-cold $70 \%$ ethanol (stored at $-20^{\circ} \mathrm{C}$ ) overnight. Subsequently, the cells were washed with phosphate-buffered saline (PBS) prior to resuspending in DNA staining solution [40 $\mu \mathrm{g} / \mathrm{ml}$ propidium iodide (PI), $250 \mu \mathrm{g} / \mathrm{ml}$ RNase in PBS with $2 \mathrm{mM}$ EDTA] for $30 \mathrm{~min}$ at $37^{\circ} \mathrm{C}$. Cell cycle distribution was analyzed using flow cytometer (FACSCalibur; BD Biosciences, Franklin Lakes, NJ, USA).

Apoptosis analysis. The apoptosis level of SW1116 and SW480 cell transfection with RPN2 siRNA or control siRNA was assessed by flow cytometric assay. The overall cell apoptosis detection procedures were similar to the previously described procedures with slight modification on the cell numbers (23). In brief, the cells were washed and detached in $2 \mathrm{ml}$ PBS with $2 \mathrm{mM}$ ethylenediaminetetraacetic acid (EDTA) and centrifuged at $15,000 \mathrm{x} \mathrm{g}$ for $5 \mathrm{~min}$. The suspended cells were stained with $250 \mu \mathrm{l}$ of hypotonic fluorochrome solution including PBS, $50 \mu \mathrm{g}$ of PI, $0.1 \%$ sodium citrate and $0.1 \%$ Triton X-100 and RNase A (100 U/ml) (BD Biosciences) for $30 \mathrm{~min}$ in the dark at room temperature. Measurements were made using a flow cytometer (BD Influx; BD Biosciences). B3 quadrant represented viable cells and B2 and B4 quadrants represented apoptotic cells.

Cell invasion and migration assays. The invasion and migration activity of the SW1116 and SW480 cells transfected with RPN2 siRNA or control siRNA were assessed by a 24-well Transwell chamber coated with or without Matrigel (BD Biosciences) on the upper surface of the membrane, with a pore size of $8 \mu \mathrm{m}$ (Sigma-Aldrich; Merck KGaA). In brief, the transfected SW1116 and SW480 cells ( $1 \times 10^{4}$ cells/well) were suspended in culture media (100 $\mu \mathrm{l}$; serum free) and then placed in the upper Transwell chamber. The lower chamber was filled with medium containing $10 \%$ FBS. After 24-h incubation, the cells that had invaded or migrated through the membrane to the lower surface were fixed, stained and counted visually under a microscope (Olympus IX71-A12FL/PH; Olympus Corporation).

Western blot analysis. Cells were seeded at a density of $5 \times 10^{5}$ cells/well in 6 -well plates after transfection with RPN2 siRNA and control siRNA for $48 \mathrm{~h}$. Each group of cells was harvested and washed twice with PBS and protein lysed in icecold radio immunoprecipitation assay buffer (RIPA; Beyotime 
Institute of Biotechnology, Shanghai, China) with freshly added $0.01 \%$ protease inhibitor PMSF (Amresco, Shanghai, China) and incubated on ice for $30 \mathrm{~min}$. Cell lysis was centrifuged at $10,000 \mathrm{x} \mathrm{g}$ for $5 \mathrm{~min}$ at $4^{\circ} \mathrm{C}$ and the supernatant (20-30 $\mu \mathrm{g}$ of protein) was run on $10 \%$ SDS-PAGE gel and electrophoretically transferred onto a nitrocellulose (NC) membrane (Millipore, Shanghai, China), and then detected with RPN2 (1:800; cat. no. ab64467), caspase-3 (1:1,000; cat. no. ab13847), cyclin D1 (1:800; cat. no. ab16663), E-cadherin (1:800; cat. no. ab15148), MMP-2 (1:1,200; cat. no. ab37150), TIMP-2 (1:1,000; cat. no. ab157386), STAT3 (1:1,000; cat. no. ab68153), phosphorylated (p-) STAT3 (1:800; cat. no. ab32143), JAK2 (1:1,200; cat. no. ab108596), p-JAK2 (1:1,000; cat. no. ab32101) proteins. Protein loading was estimated using mouse anti-GAPDH monoclonal antibody (1:2,500; cat. nos. AG019 and AF006; Beyotime Institute of Biotechnology). Blots were visualized using enhanced chemiluminescence (ECL; Thermo Fisher Scientific, Shanghai, China).

RNA isolation and RT-PCR. The expression of genes was evaluated using RT-PCR and SYBR Green I chemistry (TransStart Top Green qPCR SuperMix; TransGen Biotech, Co., Ltd., Beijing, China). Cells were seeded in 6-well plates at a density of $5 \times 10^{5}$ cells/well, cultured overnight and then treated with siRNA-RPN2 for $48 \mathrm{~h}$. Total RNA ( $2 \mu \mathrm{g})$ was extracted from cells using TRIzol reagent (Invitrogen; Thermo Fisher Scientific, Inc.) according to the manufacturer's protocol, and was reverse transcribed with the TransCript One-step gDNA Removal and cDNA Synthesis SuperMix (TransGen Biotech, Co., Ltd.). The expression of RPN2, caspase-3, cyclin D1, E-cadherin, MMP-2 and TIMP-2 mRNA in SW1116 and SW480 cells was detected by RT-PCR with the cycling parameters defined as follows: an initial cycling for $5 \mathrm{~min}$ at $95^{\circ} \mathrm{C}$, followed by 40 cycles at $95^{\circ} \mathrm{C}$ for $15 \mathrm{sec}, 30 \mathrm{sec}$ at $60^{\circ} \mathrm{C}$ and $30 \mathrm{sec}$ at $72^{\circ} \mathrm{C}$. The primers used for the amplification of the indicated genes were designed using the Primer Express software (Applied Biosystems; Thermo Fisher Scientific, Foster City, CA, USA). Primers used were as follows: RPN2, forward, 5'- CAAAGTCACCGGACAAGGTC-3' and reverse, 5'-TGG TGTTCCGAAGTTGGTCA-3' (product: 142 bp); caspase-3, forward, 5'-CTATGGCTACGCTGTGGAGA-3' and reverse, 5'-TGTAGAAGCCAGGGCTCATC-3' (product: $110 \mathrm{bp}$ ); cyclin D1, forward, 5'-ATAGATGCCAGGCAGAGACC-3' and reverse, 5'-ACTGCCTGTTCCCACTACTC-3' (product: 123 bp); E-cadherin, forward, 5'-TGCCAACTGGCTGG AGATTA-3' and reverse, 5'-AGTGTCCCTGTTCCAGTAGC-3' (product: 156 bp); MMP-2, forward, 5'-CTACTGAGTGGCCG TGTTTG-3' and reverse, 5'-TCCCTGAGGTTCTCTTGCTG-3' (product: $174 \mathrm{bp}$ ); TIMP-2, forward, 5'-AGCATTTGACCCAG AGTGGA-3' and reverse, 5'-GGAGAACCAAAGACGGG AGA-3' (product: $111 \mathrm{bp}$ ); GAPDH, forward, 5'-ACCCAGA AGACTGTGGATGG-3' and reverse, 5'-TCAGCTCAGGGAT GACCTTG-3' (product: $124 \mathrm{bp}$ ). The relative expression levels were analyzed using the $2^{-\Delta \Delta \mathrm{Ct}}$ method. GAPDH was used as internal control to monitor RT-PCR efficiency. All RT reactions were performed in triplicate.

Statistical analysis. All results are presented as the mean \pm SD of three independent experiments and the data were processed with SPSS 13.0 software (SPSS, Inc., Chicago, IL, USA). Survival analysis was used in the analysis of the information concerning CRC cancer patients. Data for multiple comparisons were subjected to one-way ANOVA and Chi-square test. $\mathrm{P}<0.05$ was considered to indicate a statistically significant difference.

\section{Results}

Overexpression of RPN2 is observed in CRC specimens and cell lines and associated with poor survival of CRC patients. In order to determine the biological role of RPN2 in CRC tumor tissues, RT-PCR and western blot analysis were used to detect the expression levels of RPN2 in tissues of $43 \mathrm{CRC}$ patients and their adjacent normal tissues. As displayed in Fig. 1A and B, the RPN2 expression levels were higher in CRC tissues compared with the adjacent normal tissues. Immunohistochemical staining results further demonstrated that RPN2 was highly expressed in CRC tissues (Fig. 1C). Subsequently, a univariate survival analysis indicated that the survival rate of patients with high expression of RPN2 and the survival rate of patients with low expression of RPN2 in 200 days was similar. As time passed, the survival rate of patients with highly expressed RNP2 was reduced (Fig. 1D). Subsequently, the mRNA and protein expression levels of RPN2 in colon cancer cells, SW1116, SW480, LoVo, SW403 and SW620, as well as normal colon cells NCM460 were determined. We revealed that RPN2 was positively identified in colon cancer cell lines, but weakly expressed in normal colon cells (Fig. 1E-G). Since the RPN2 expression levels in SW1116 and SW480 cells were higher than that of LoVo, SW403 and SW620 cells, SW1116 and SW480 cells were used for the following experiment.

siRNA-mediated knockdown of RPN2 in SW1116 and SW480 cells inhibits cell viability. In order to validate whether RPN2 functions in cell proliferation, SW1116 and SW480 cells were used for detecting changes in cell viability after RPN2 knockdown by siRNA interference. As displayed in Fig. 2A-F, RT-PCR and western blot analysis at $48 \mathrm{~h}$ after transfection demonstrated that RPN2 knockdown in SW1116 and SW480 cells significantly decreased the mRNA and protein levels of RPN2. The cell proliferation was further assessed in SW1116 and SW480 cells using CCK-8 assay. After $48 \mathrm{~h}$, cell proliferation was reduced to $53 \%$ for SW1116 cell and to $45 \%$ for SW480 cells (Fig. 2G and $\mathrm{H}$ ). These results indicated that RPN2 siRNA interference significantly inhibited cell proliferation.

siRNA-mediated knockdown of RPN2 induces G1-phase cellcycle arrest and apoptosis in SW1116 and SW480 cells. In order to further confirm the effect of RPN2 on cell proliferation, flow cytometry was used to detect the cell cycle and apoptosis. After SW1116 and SW480 cell transfection with RPN2 siRNA or control siRNA, there was no significant difference in cell cycle and apoptosis between the control and the mock groups in SW1116 and SW480 cells (Fig. 3). The results demonstrated that the knockdown of RPN2 significantly increased G1-phase cell population and increased the apoptosis rate $(27.9 \pm 1.9 \%)$ in SW1116 cells (Fig. 3A and B). Then, the knockdown of RPN2 significantly increased G1-phase cell population and decreased S-phase cell population in 
A

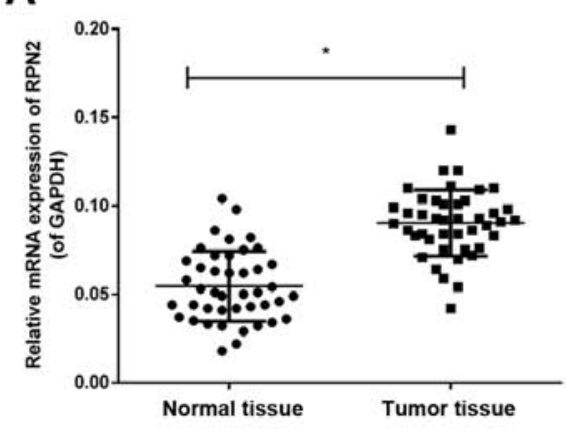

B

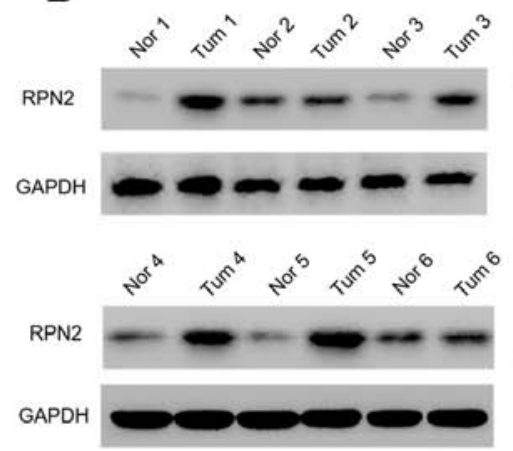

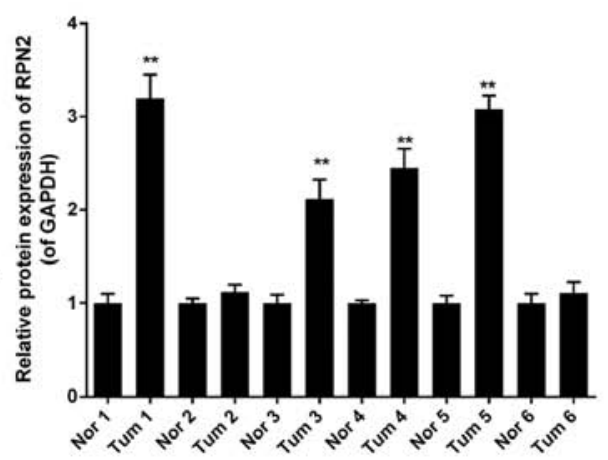

C

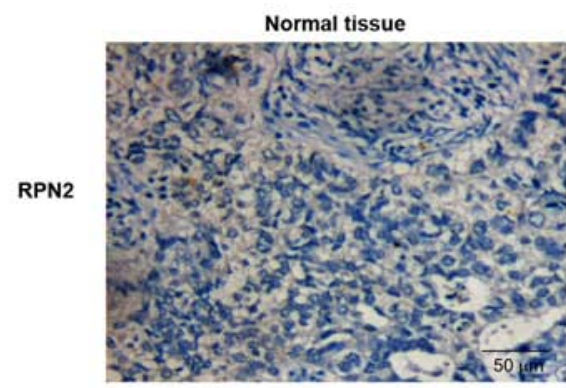

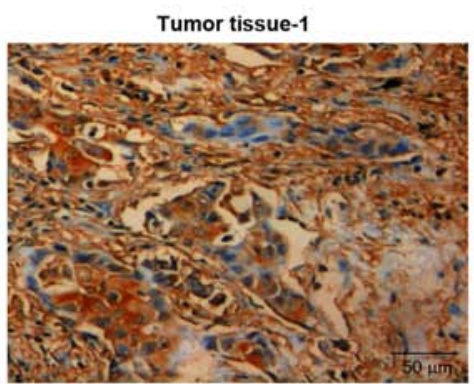

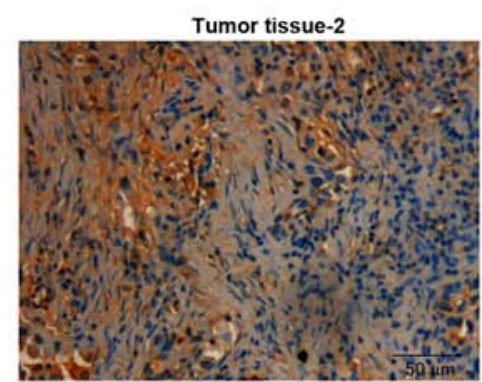

D

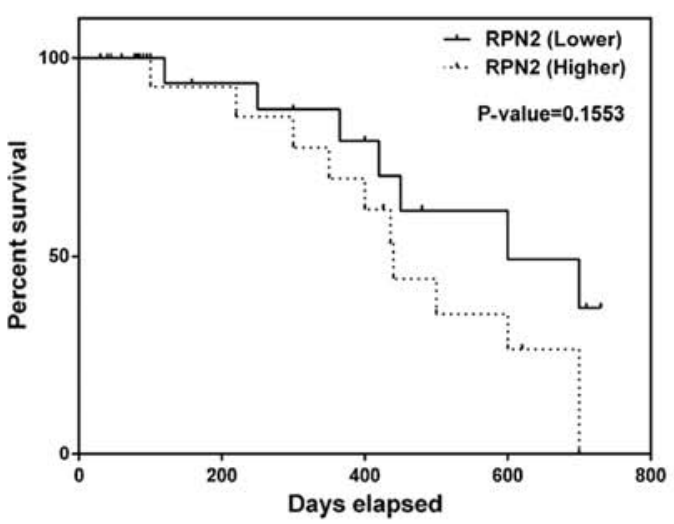

$\mathbf{F}$

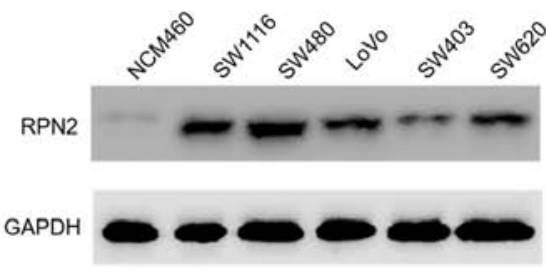

$\mathbf{E}$

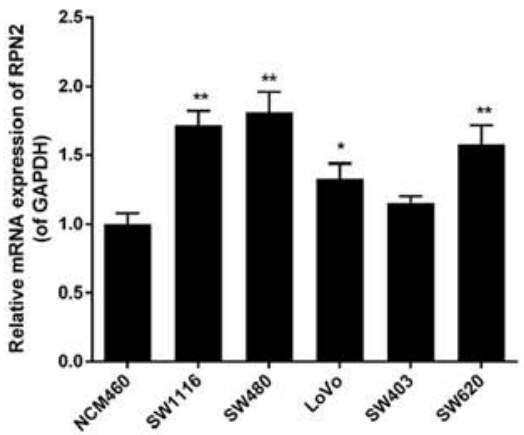

G

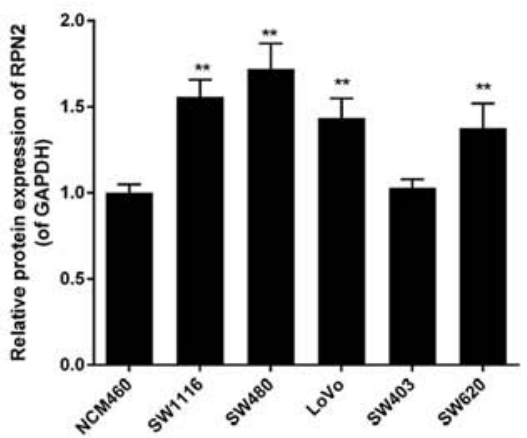

Figure 1. Expression of RPN2 in CRC tissues and cell lines. (A) The expression level of RPN2 detected by RT-PCR in 43 paired CRC tissues and adjacent normal colon tissues. (B) The expression level of RPN2 detected by western blot analysis in 43 paired CRC tissues and adjacent normal colon tissues. (C) The expression of RPN2 was determined by immunohistochemistry staining. (D) The survival rate of 43 CRC patients which revealed that patients with higher RPN2 ( $n=26)$ expression had shorter survival rate than patients with lower RPN2 ( $=17)$ expression. (E-G) The expression of RPN2 in five CRC cell lines and a normal colon cell line, NCM460, was detected by RT-PCR and western blot analysis. GAPDH was also detected as the control of sample loading. Data are expressed as the mean \pm SD for three independent experiments ${ }^{*} \mathrm{P}<0.05$ and ${ }^{* *} \mathrm{P}<0.01$ vs. normal colon NCM460 cells.

SW480 cell (Fig. 3C). RPN2 downregulation in SW480 cells indicated a significant increase in apoptosis rate by $28.8 \pm 3.2 \%$ (Fig. 3D). Collectively, these results demonstrated that the knockdown of RPN2 inhibited cell proliferation and promoted apoptosis of CRC cells.
siRNA-mediated knockdown of RPN2 suppresses the abilities of migration and invasion in SW1116 and SW480 cells. The abilities of migration and invasion play a vital role in tumor metastasis. Therefore, we further investigated the effect of siRNA-mediated knockdown of RPN2 on the abilities of 
A

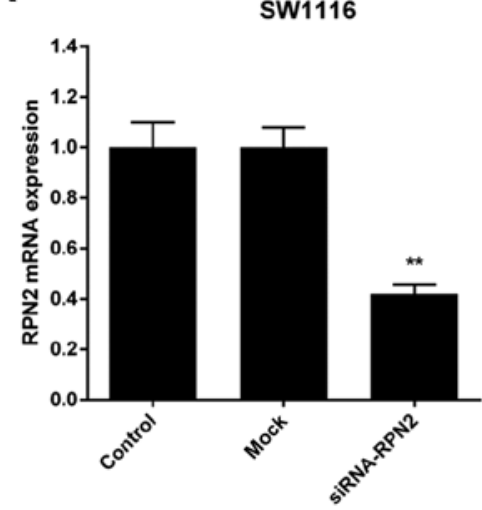

D

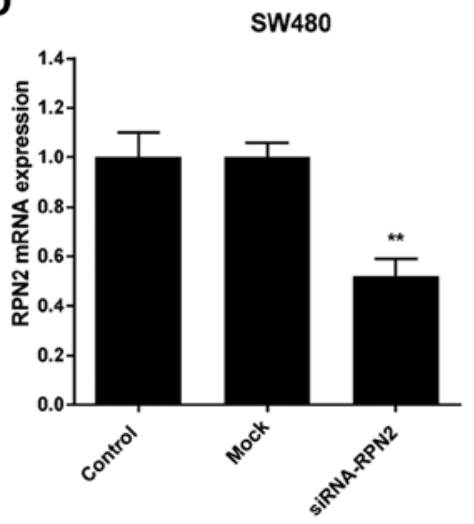

B

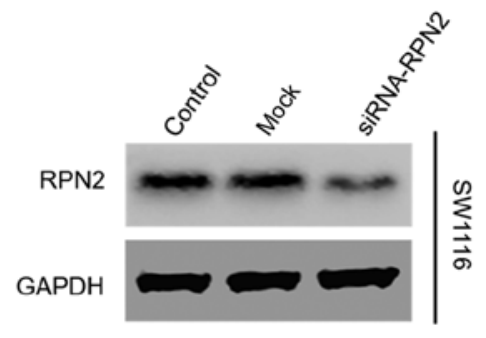

C

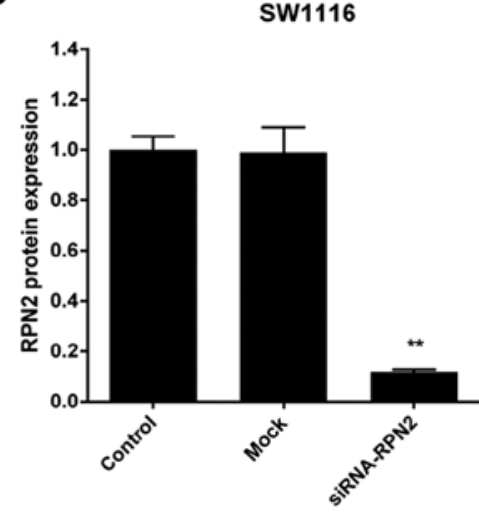

F

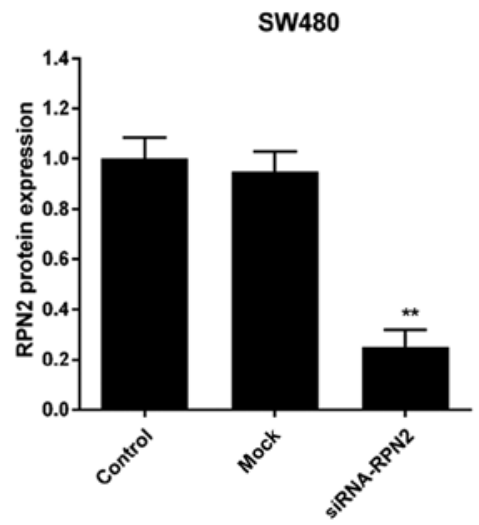

G

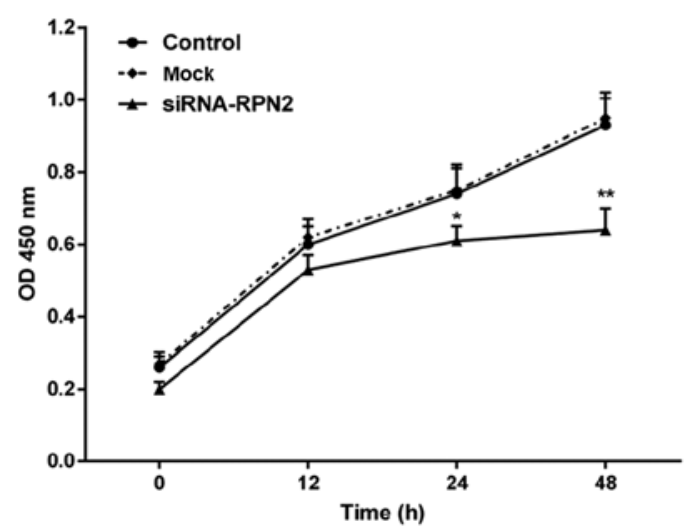

H

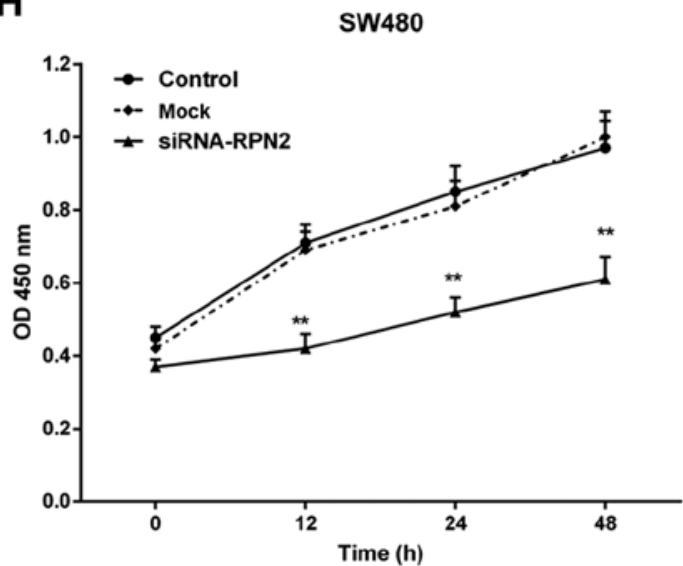

Figure 2. Changes in RPN2 expression and cell viability in RPN2 siRNA transfected SW1116 and SW480 cells. (A) The mRNA expression level of RPN2 was detected after RPN2 siRNA transfection of SW1116 cells for $48 \mathrm{~h}$ by RT-PCR. (B and C) The protein expression level of RPN2 was detected after RPN2 siRNA transfection of SW1116 cells for $48 \mathrm{~h}$ by western blot analysis. (D) The mRNA expression level of RPN2 was detected after RPN2 siRNA transfection of SW480 cells for $48 \mathrm{~h}$ by RT-PCR. (E and F) The protein expression level of RPN2 was detected after RPN2 siRNA transfection of SW480 cells for $48 \mathrm{~h}$ by western blot analysis. GAPDH was also detected as the control of sample loading. Data are expressed as the mean \pm SD for three independent experiments. ${ }^{* *} \mathrm{P}<0.01$ vs. control and mock. (G and H) Cell viability was detected after RPN2 siRNA transfection of SW1116 and SW480 cells for 12, 24 and $48 \mathrm{~h}$ by CCK-8 assay. Data are expressed as the mean \pm SD for three independent experiments. ${ }^{*} \mathrm{P}<0.05$ and ${ }^{* *} \mathrm{P}<0.01$ vs. control and mock.

migration and invasion in colon cancer cell lines (SW1116 and SW480 cells). Consistently, as displayed in Fig. 4, the downregulation RPN2 in SW1116 cells significantly reduced cell migration by $61.7 \%$ and the cell invasion by $59.4 \%$ compared with control cells (Fig. 4A-C). In addition, we demonstrated that RPN2 downregulation in SW480 cells significantly suppressed cell migration by $49.5 \%$ and the cell invasion by
59.7\% compared with the control cells (Fig. 4D-F). Collectively, these results demonstrated that the knockdown of RPN2 inhibited the migration and invasion abilities of CRC cells.

siRNA-mediated knockdown of RPN2 regulates the expression levels of caspase-3, cyclin D1, E-cadherin, MMP-2 and TIMP-2 in SW1116 and SW480 cells. In order to further inves- 

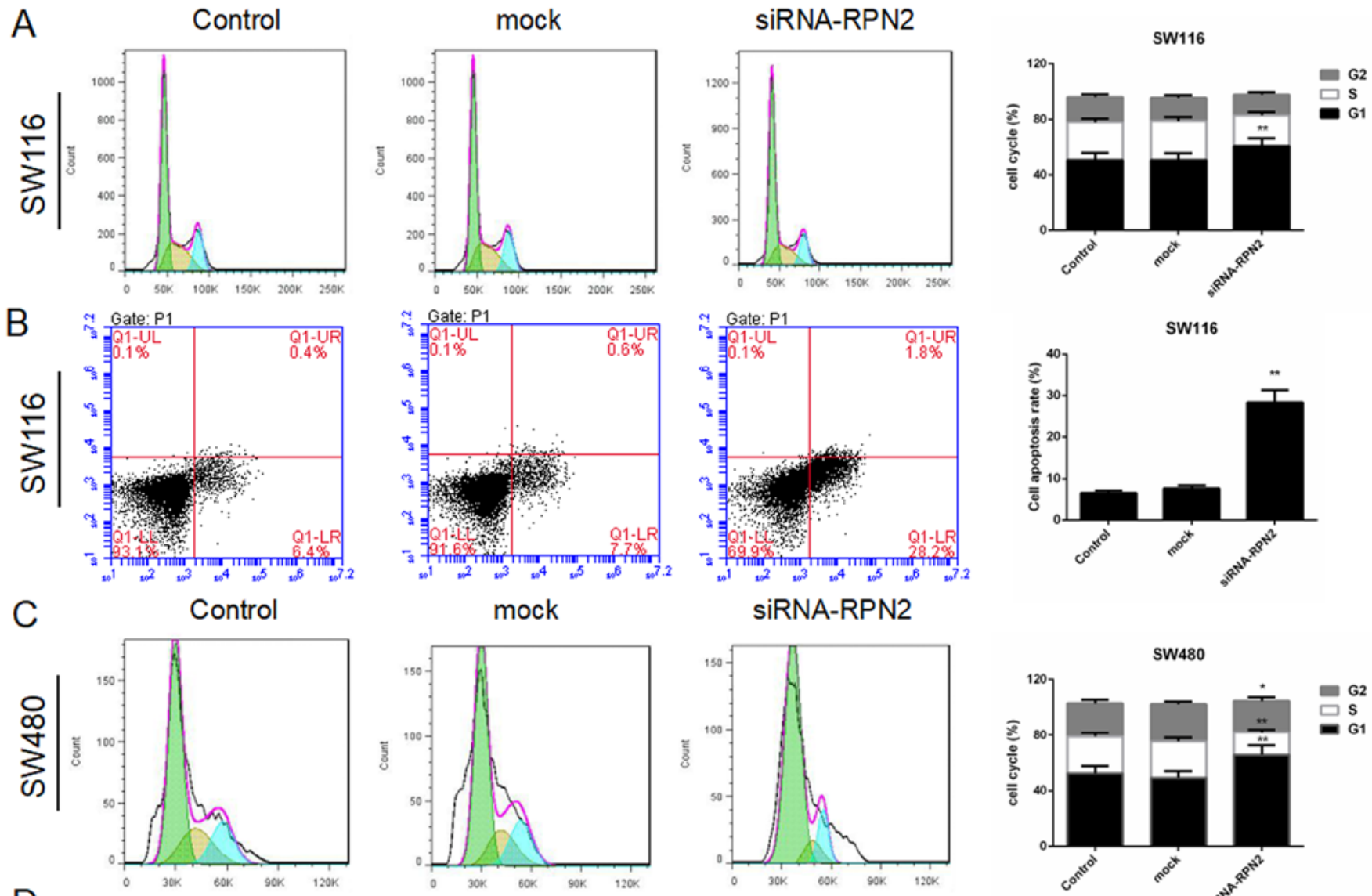

mock

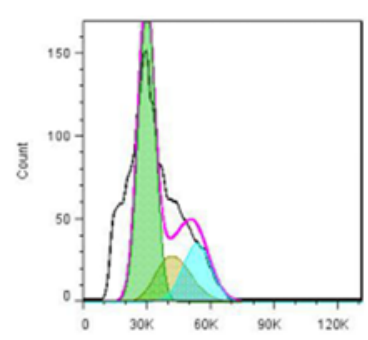

siRNA-RPN2
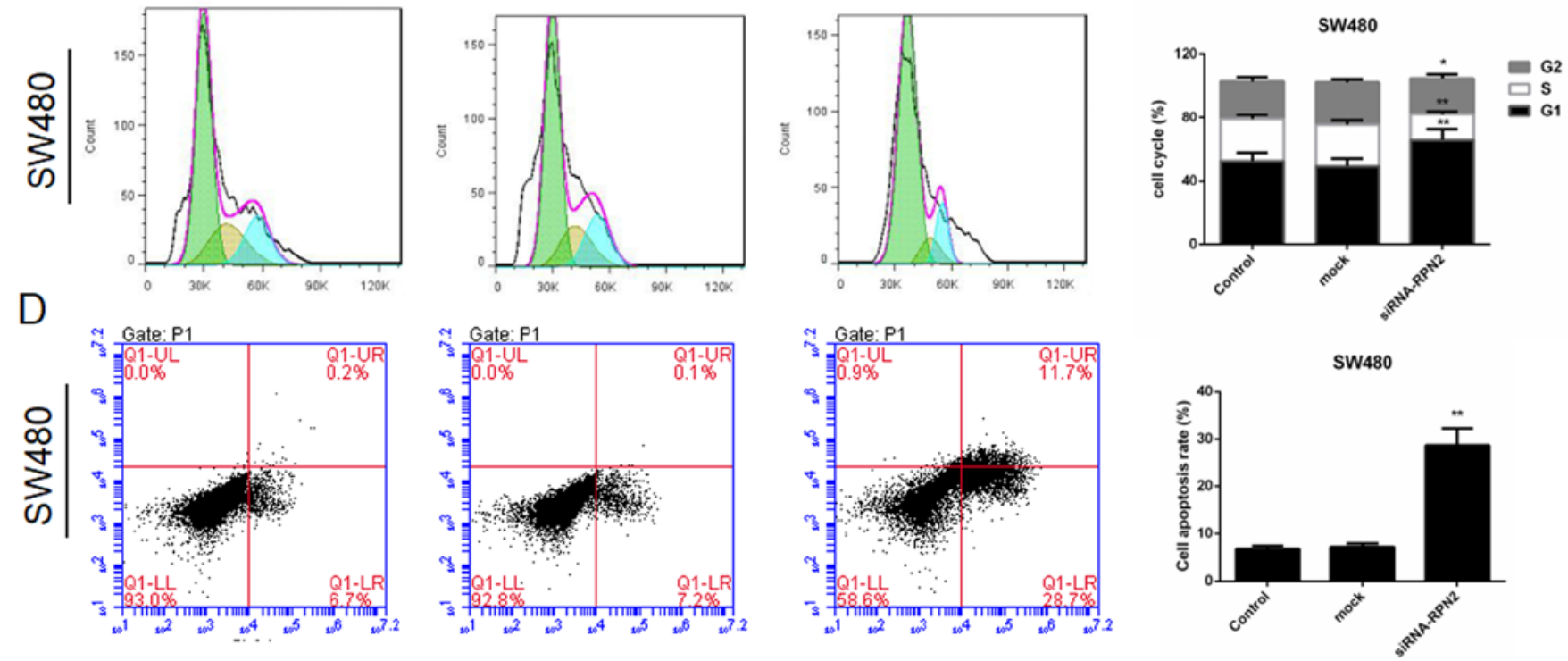

Figure 3. Changes in cell cycle and apoptosis in RPN2 siRNA transfected SW1116 and SW480 cells. (A) Cell cycle was detected after RPN2 siRNA transfection of SW1116 cells for $48 \mathrm{~h}$ using flow cytometry and PI staining. (B) Cell apoptosis was detected after RPN2 siRNA transfection of SW1116 cells for $48 \mathrm{~h}$ using flow cytometry and Annexin V-FITC/PI staining. (C) Cell cycle was detected after RPN2 siRNA transfection of SW480 cells for $48 \mathrm{~h}$ using flow cytometry and PI staining. (D) Cell apoptosis was detected after RPN2 siRNA transfection of SW480 cells for $48 \mathrm{~h}$ using flow cytometry and Annexin V-FITC/PI staining. Data are expressed as the mean $\pm \mathrm{SD}$ for three independent experiments. ${ }^{*} \mathrm{P}<0.05$ and ${ }^{* *} \mathrm{P}<0.01$ vs. control and mock.

tigate the related mechanisms involved in RPN2-mediated cell proliferation, migration and invasion in CRC cells, the expression levels of caspase-3, cyclin D1, E-cadherin, MMP-2 and TIMP-2 were detected by means of RT-PCR and western blot analysis. As displayed in Fig. 5, the apoptosis-related protein (caspase-3) expression was increased and the cell cycle-related protein (cyclin D1) expression was decreased in SW1116 cells (Fig. 5A and B). In addition, migration- and invasion-related proteins including E-cadherin, MMP-2 and TIMP-2 were detected by RT-PCR and western blot analysis. The results indicated that E-cadherin and TIMP-2 expression levels were increased and MMP-2 expression level was decreased after SW1116 cell transfection with RPN2 siRNA (Fig. 5A and B). Concerning SW480 cells, the knockdown of RPN2 increased the expression levels of caspase-3, E-cadherin and TIMP-2 and decreased the expression levels of cyclin D1 and MMP-2 after SW1116 cell transfection with RPN2 siRNA (Fig. 5C and D).

siRNA-mediated knockdown of RPN2 blocks the STAT3/JAK2 signaling in SW1116 and SW480 cells. After 48 h of RPN2 siRNA transfection, the phosphorylation protein levels of STAT3 and JAK2 in SW1116 and SW480 cells were determined by western blot analysis. The results demonstrated that there was no change in the total protein expression levels of JAK2 and STAT3 in SW1116 and SW480 cells transfected with RNP2 siRNA. RPN2 downregulation suppressed the phosphorylation levels of JAK2 and STAT3 (Fig. 6). Namely, the relative expression levels of p-JAK2 and p-STAT3 were significantly decreased after RPN2 siRNA interference (Fig. 6). Total JAK2 (t-JAK2) and STAT3 (t-STAT3) protein expression level had not any change. It was demonstrated that knockdown of RPN2 
A

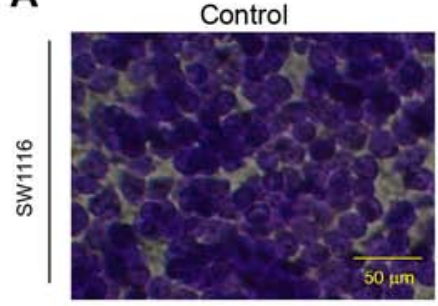

B

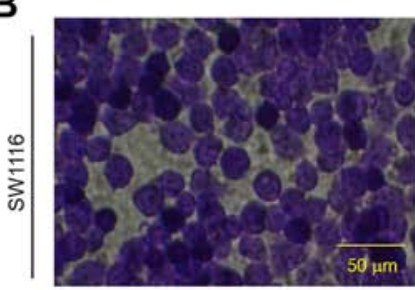

D

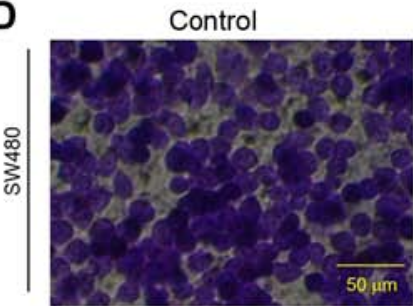

E

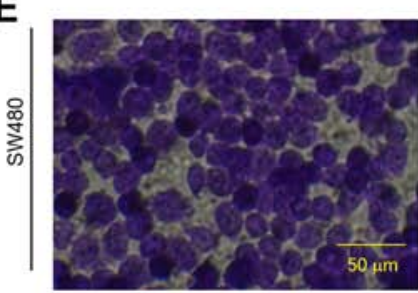

Mock
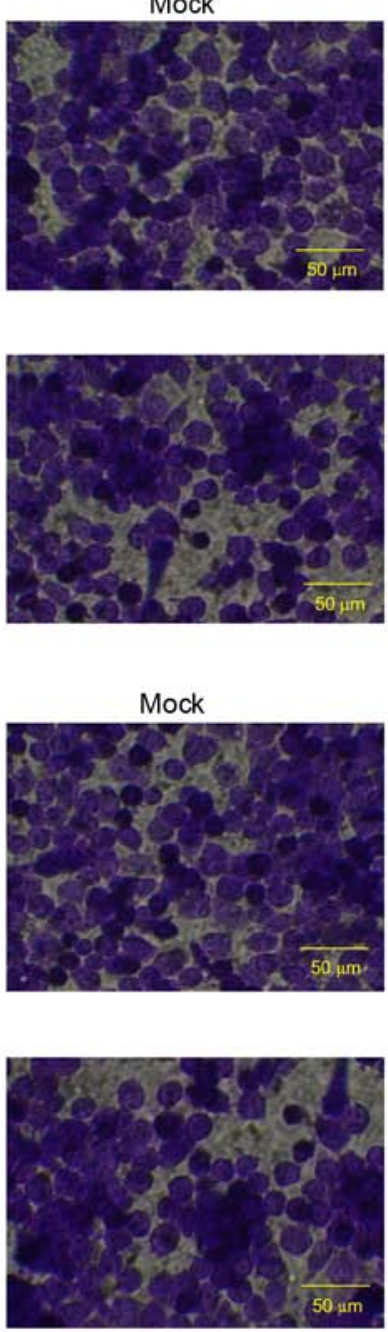

siRNA-RPN2
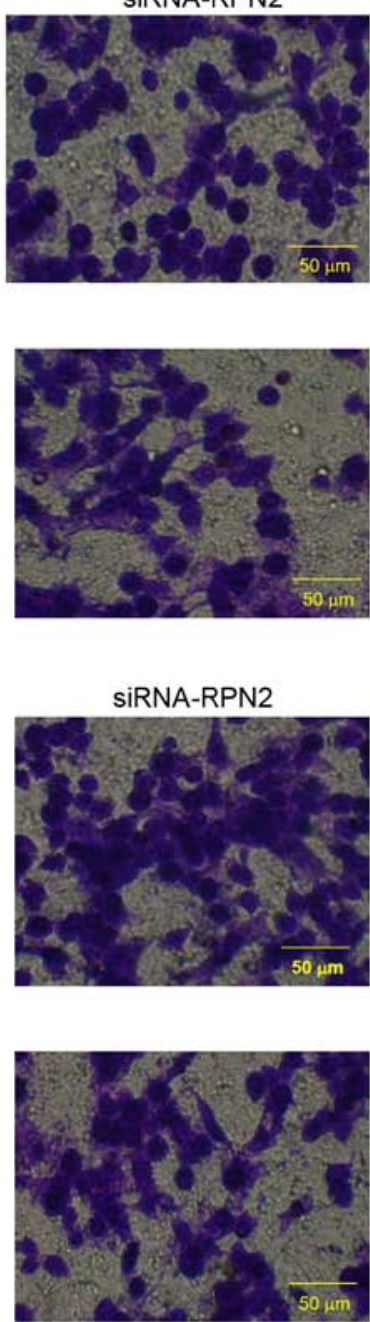

C

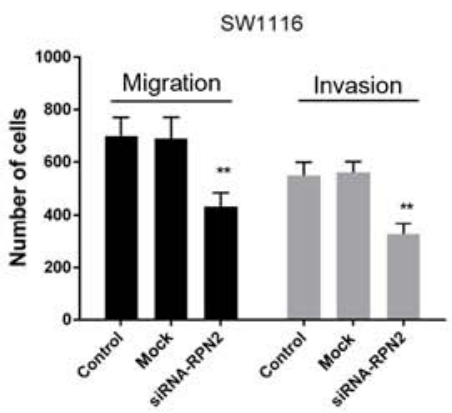

F

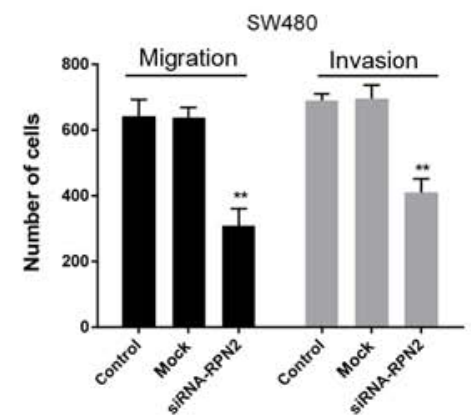

Figure 4. Changes in cell migration and invasion in RPN2 siRNA transfected SW1116 and SW480 cells. (A-C) Cell migration and invasion was evaluated by Transwell assay after RPN2 siRNA transfection of SW1116 cells. (D-F) Cell migration and invasion was evaluated by Transwell assay after RPN2 siRNA transfection of SW480 cells. Data were presented as mean $\pm \mathrm{SD}, \mathrm{n}=3,{ }^{* *} \mathrm{P}<0.01$ vs. control and mock.

by siRNA interference inhibited the activation of STAT3/ JAK2 signaling pathway in CRC cells.

\section{Discussion}

Tumor cells have the characteristics of malignant proliferation, migration and invasion (24) which significantly influence the development of cancer. Therefore, identifying specific genetic markers associated with tumor growth and metastasis may be useful to study cancer progression. According to the literature, an intensive expression of RPN2 was found in CRC (16). But the related molecular mechanism remains unknown. In the present study, we collected 43 samples of CRC tissues and benign CRC tissues surgically removed in our hospital from 2014 to 2017. Subsequently, the experiment results indicated that RPN2 was highly expressed in CRC tissues and associated with poor survival of CRC patients (Fig. 1A-D). It was identical with those reported in literature. In order to further verify this result, the expression levels of RPN2 in colon cancer cell lines (SW1116, SW480, LoVo, SW403 and SW620) was determined by means of RT-PCR and western blot analysis.
We found that RPN2 was highly expressed in CRC cell lines, especially SW1116 and SW480 cells (Fig. 1D and E). These results clearly indicated that RPN2 is an important gene in the development of CRC. Therefore, the function and related mechanisms of RPN2 should be further investigated.

Concerning the role of RPN2 in CRC, it was reported that protein glycation plays an important role in the regulation of cell function by affecting protein stability, localization and secretion (12). RPN2, as a kind of glycoprotein, exists in eukaryotic organisms and was involved in the development of breast, gastric and esophageal squamous cell cancer $(12,13,15)$. Judging from the above-mentioned results, we hypothesized that RPN2 may regulate the proliferation, apoptosis, migration and invasion in CRC. Subsequently, the knockdown of RPN2 by siRNA interference was transfected into SW1116 and SW480 cells. In addition, our results indicated that the siRNA interference vectors targeting the RPN2 gene were successfully transfected into CRC cells with high expression of RPN2 and inhibited cell viability (Fig. 2). Low expression of RPN2 suppressed the process of cell cycle, restraining cells in the G1-phase, inhibiting cell proliferation and promoting cell 
A

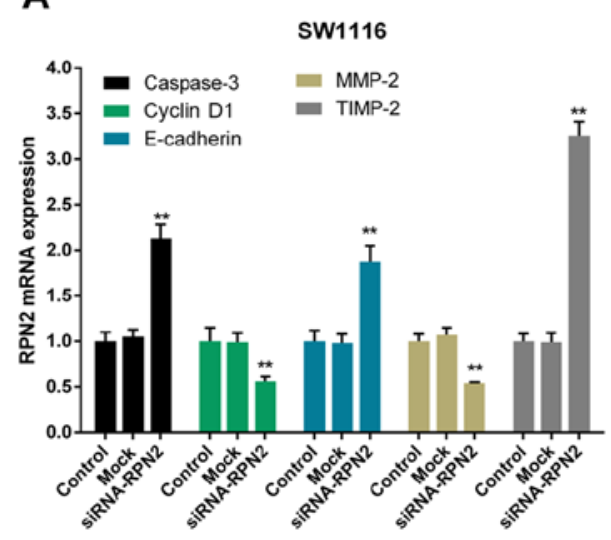

C

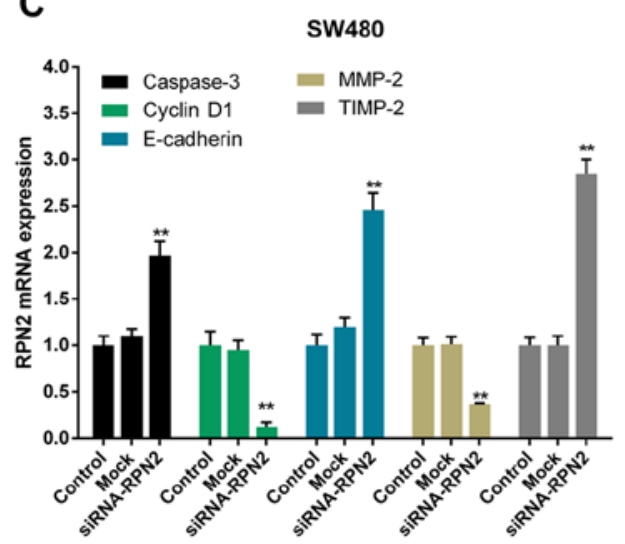

B

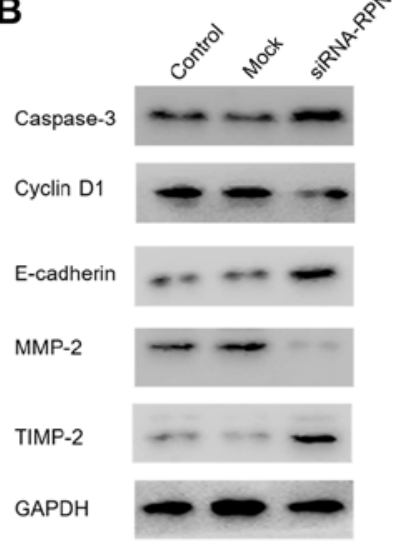

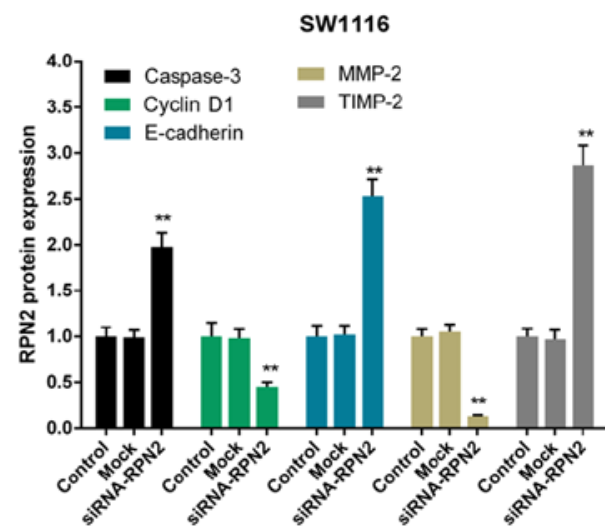

D

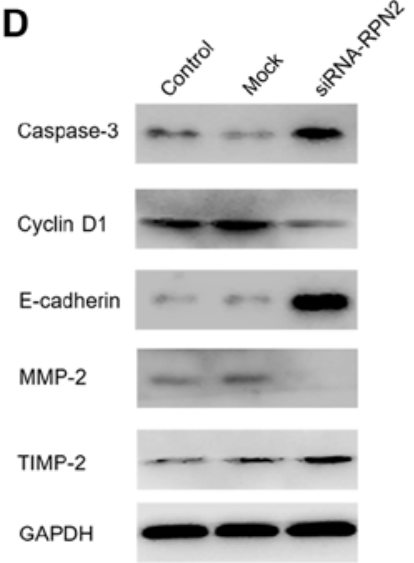

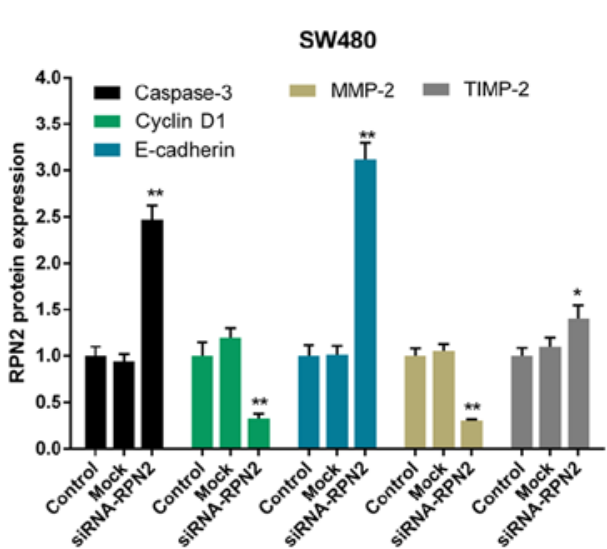

Figure 5. Changes in the expression levels of caspase-3, cyclin D1, E-cadherin, MMP-2 and TIMP-2 on RPN2 siRNA transfection of SW1116 and SW480 cells (A) The mRNA expression levels of caspase-3, cyclin D1, E-cadherin, MMP-2 and TIMP-2 were detected after RPN2 siRNA transfection of SW1116 cells for $48 \mathrm{~h}$ by RT-PCR. (B) The protein expression levels of caspase-3, cyclin D1, E-cadherin, MMP-2 and TIMP-2 were detected after RPN2 siRNA transfection of SW1116 cells for $48 \mathrm{~h}$ by western blot analysis. (C) The mRNA expression levels of caspase-3, cyclin D1, E-cadherin, MMP-2 and TIMP-2 were detected after RPN2 siRNA transfection of SW480 cells for $48 \mathrm{~h}$ by RT-PCR. (D) The protein expression levels of caspase-3, cyclin D1, E-cadherin, MMP-2 and TIMP-2 were detected after RPN2 siRNA transfection of SW480 cells for $48 \mathrm{~h}$ by western blot analysis. GAPDH was also detected as the control of sample loading. Data are expressed as the mean \pm SD for three independent experiments. ${ }^{* * *} \mathrm{P}<0.01$ vs. control and mock.

apoptosis (Fig. 3). We further determined that the migration and invasion abilities in cells transfected with RPN2 siRNA were significantly reduced (Fig. 4). The above-mentioned observations indicated that RPN2 regulated cell proliferation, apoptosis, migration and invasion. Yet, the related mechanisms need to be further researched.

Cell proliferation and apoptosis is a process of dynamic equilibration (25). Apoptosis suppression drive cells to escape death and leads to cell abnormal proliferation, further causing the occurrence and development of tumors $(26,27)$. The members of the caspase family were activated in the whole process of apoptosis. Caspase-3 is downstream gene in the apoptosis signaling pathway. In general, the activation of caspase- 8 leads to the release of caspase- 9 to induce the activation of caspase-3, and ultimately to cause apoptosis (28). It is the most common apoptosis pathway in the human organism. Therefore, we detected the expression of caspase- 3 after cells were transfected with RPN2 siRNA and control siRNA. In addition, our results revealed that caspase-3 expression was significantly increased in cells transfected with RPN2 siRNA (Fig. 5). Cell cycle is a complex process. Once the body damage induced by internal and external causes cell cycle arrest, and the apoptosis could be induced when the damage could not be repaired on time (29). Therefore, the developments of tumor are linked with progressive dysregulation of cell cycle and cell cycle is closely associated with cell apoptosis (30). Cyclin D1 is a key protein of cell proliferation signaling in G1-phase and overexpression of cyclin D1 promotes the G1-S-phase transition of the cell cycle to cause abnormal cell proliferation (31). It has been reported that cyclin D1 was highly expressed in CRC (32). In our results, the expression levels of cyclin D1 were decreased in cell transfection with RPN2 siRNA (Fig. 5). Migration and invasion are the most important biological characteristics in tumors. Low expression of E-cadherin would reduce the adhesion ability to further lead to EMT (33). MMP-2 degraded cell matrix to promote the ability to break through cell basement membrane. TIMP-2, as natural inhibitors of MMP, can affect the combination of MMP-2 and substrate (34). Therefore, E-cadherin, MMP-2 and TIMP-2 were considered as marked proteins in the process of migration and invasion in many types of cancer. Our results indicated that E-cadherin and TIMP-2 expression 
A
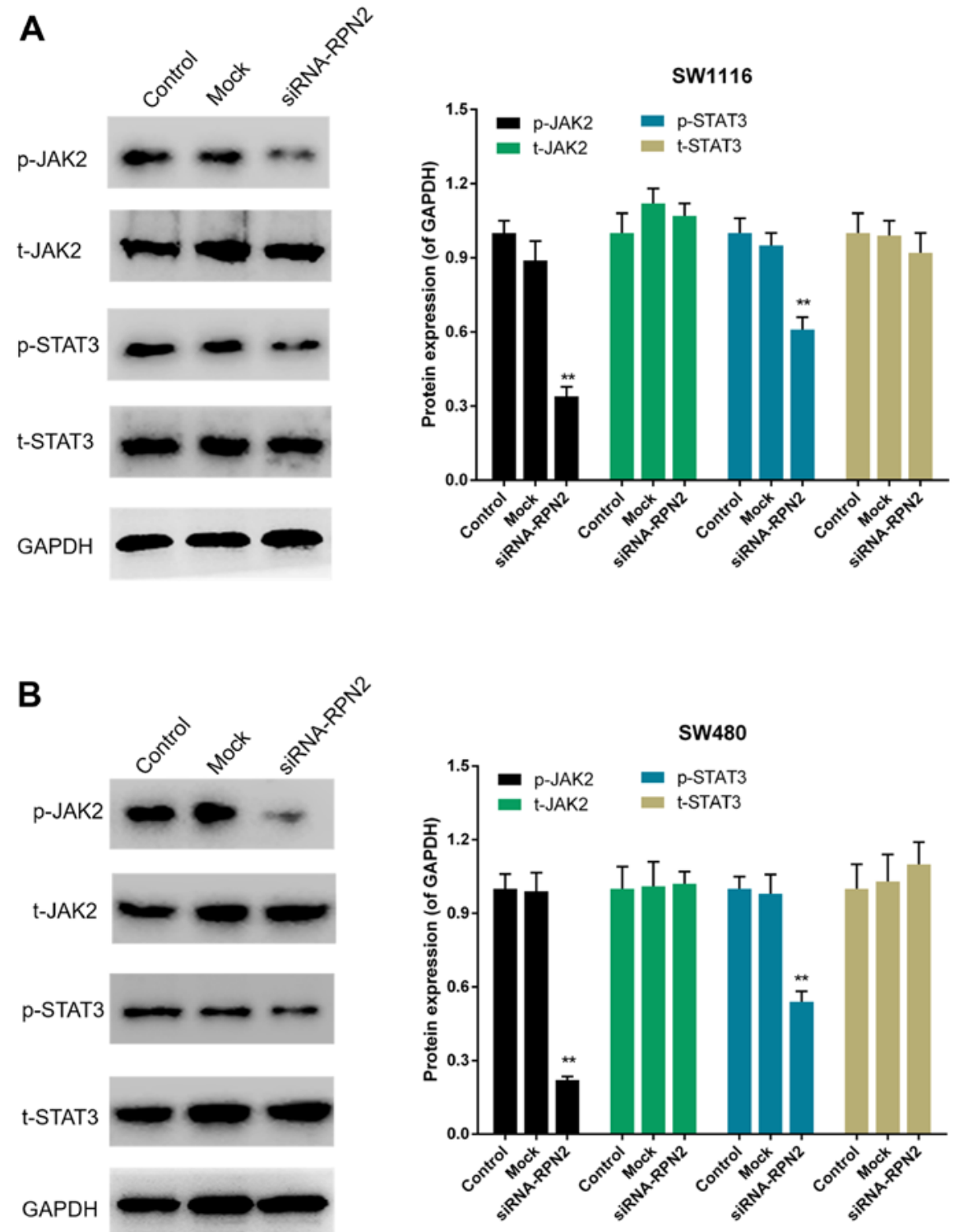

Figure 6. RPN2 siRNA inhibits the activation of JAK2/STAT3 signaling pathway in SW1116 and SW480 cells. (A) The phosphorylation levels of JAK2 and STAT3 proteins were detected by western blot analysis in the RPN2 siRNA group of SW1116 cells. (B) The phosphorylation levels of JAK2 and STAT3 proteins were detected by western blot analysis in the RPN2 siRNA group of SW480 cells. GAPDH was also detected as the control of sample loading. Data are expressed as the mean $\pm \mathrm{SD}$ for three independent experiments. ${ }^{* *} \mathrm{P}<0.01$ vs. control and mock

was increased and MMP-2 expression was decreased after cells transfected with siRNA interference vectors targeting the RPN2 gene (Fig. 5). Collectively, RPN2 siRNA affected the expression levels of caspase-3, cyclin D1, E-cadherin, MMP-2 and TIMP-2 to inhibit cell proliferation, induce cell apoptosis, suppress cell migration and invasion.

JAK2/STAT3 signal pathway is a key signal transduction pathway and plays an important role in maintaining a constant internal environment (35). The activation of JAK affects cell proliferation, apoptosis, migration and invasion. STAT3 is closely associated with signaling pathway in many tumors $(17,19)$. In addition, the activation of STAT3 can upregulate anti-apoptosis genes to inhibit cell apoptosis $(20,21)$. It was reported that some extracts or genes promoted cell apoptosis and inhibited cell migration and invasion and caused cycle arrest in kidney, breast, ovarian and colon cancer by inhibiting the activation of STAT3 (16,36-39). Therefore, the phosphorylation levels of JAK2 and STAT3 were further determined in cells transfected with RPN2 siRNA. We observed that the phosphorylation levels of JAK2 and STAT3 were significantly decreased after the cells were transfected with RPN2 siRNA (Fig. 6). It was revealed that RPN2 siRNA inhibited the activation of JAK2/STAT3. It was further demonstrated that RPN2 may be a target gene of JAK2/STAT3 signal pathway.

According to the above-mentioned results, downregulation of RPN2 inhibited cell proliferation, caused cell-cycle arrest, promoted cell apoptosis and suppressed the abilities of cell migration and invasion, regulated the expression levels of apoptosis- and cycle-related genes (caspase-3 and cyclin D1) and invasion- and metastatic-related genes (E-cadherin, MMP-2 and TIMP-2) and inhibited the activation of JAK2/STAT3 signaling pathway. Therefore, the present study indicated that implicate signaling through JAK2/STAT3 as a critical mechanism by which RPN2 siRNA may affect cell proliferation, apoptosis, migration and invasion in CRC. 


\section{Acknowledgements}

Not applicable.

\section{Funding}

The present study was supported by a fund of Shanxi Province Science and Technology Development Research project (no. 2010R034-2).

\section{Availability of data and materials}

The datasets used and/or analyzed during the current study areavailable from the corresponding author on reasonable request.

\section{Authors' contributions}

$\mathrm{CB}$ and $\mathrm{BJ}$ designed and performed the experiments; $\mathrm{BJ}$ contributed to the data analysis; $\mathrm{CB}$ enrolled patients and measured the RNA levels in the clinical samples; CB initiated the work and wrote the manuscript. All authors read and approved the manuscript and agree to be accountable for all aspects of the research in ensuring that the accuracy or integrity of any part of the work are appropriately investigated and resolved.

\section{Ethics approval and consent to participate}

The use of human tissues was approved by the Ethics Committee of Huai'an First People's Hospital.

\section{Consent for publication}

Not applicable.

\section{Competing interests}

The authors declare that they have no competing interests.

\section{References}

1. Niknami Z, Eslamifar A, Emamirazavi A, Ebrahimi A and Shirkoohi R: The association of vimentin and fibronectin gene expression with epithelial-mesenchymal transition and tumor malignancy in colorectal carcinoma. EXCLI J 16: 1009-1017, 2017.

2. Xu RH, Shen L, Li J, Xu JM, Bi F, Ba Y, Bai L, Shu YQ, Liu TS, $\mathrm{Li} \mathrm{YH}$, et al: Expert consensus on maintenance treatment for metastatic colorectal cancer in China. Chin J Cancer 35: 13, 2016

3. Shin CM, Han K, Lee DH, Choi YJ, Kim N, Park YS and Yoon H: Association among obesity, metabolic health, and the risk for colorectal cancer in the general population in Korea using the National Health Insurance Service-National Sample Cohort. Dis Colon Rectum 60: 1192-1200, 2017.

4. Lopes-Ramos CM, Barros BP, Koyama FC, Carpinetti PA, Pezuk J, Doimo NT, Habr-Gama A, Perez RO and Parmigiani RB: E2F1 somatic mutation within miRNA target site impairs gene regulation in colorectal cancer. PLoS One 12: e0181153, 2017.

5. Jayasekara H, English DR, Haydon A, Hodge AM, Lynch BM, Rosty C, Williamson EJ, Clendenning M, Southey MC1, Jenkins MA, et al: Associations of alcohol intake, smoking, physical activity and obesity with survival following colorectal cancer diagnosis by stage, anatomic site and tumor molecular subtype. Int J Cancer 142: 238-250, 2018.
6. Altobelli E, Latella G, Morroni M, Licini C, Tossetta G, Mazzucchelli R, Profeta VF, Coletti G, Leocata P, Castellucci M, et al: Low HtrA1 expression in patients with long standing ulcerative colitis and colorectal cancer. Oncol Rep 38: 418-426, 2017.

7. Nandra R, Parry M, Forsberg J and Grimer R: Can a bayesian belief network be used to estimate 1-year survival in patients with bone sarcomas? Clin Orthop Relat Res 475: 1681-1689, 2017.

8. Yogarajah $M$ and Tefferi A: Leukemic transformation in myeloproliferative neoplasms: A literature review on risk, characteristics, and outcome. Mayo Clin Proc 92: 1118-1128, 2017.

9. Fujieda Y, Amengual O, Matsumoto M, Kuroki K, Takahashi H, Kono M, Kurita T, Otomo K, Kato M, Oku K, et al: Ribophorin II is involved in the tissue factor expression mediated by phosphatidylserine-dependent antiprothrombin antibody on monocytes. Rheumatology (Oxford) 55: 1117-1126, 2016.

10. Ono M, Tsuda H, Kobayashi T, Takeshita F, Takahashi RU, Tamura K, Akashi-Tanaka S, Moriya T, Yamasaki T, Kinoshita T, et al: The expression and clinical significance of ribophorin II (RPN2) in human breast cancer. Pathol Int 65: 301-308, 2015.

11. Honma K, Iwao-Koizumi K, Takeshita F, Yamamoto Y, Yoshida T, Nishio K, Nagahara S, Kato K and Ochiya T: RPN2 gene confers docetaxel resistance in breast cancer. Nat Med 14: 939-948, 2008.

12. Tominaga N, Hagiwara K, Kosaka N, Honma K, Nakagama H and Ochiya T: RPN2-mediated glycosylation of tetraspanin CD63 regulates breast cancer cell malignancy. Mol Cancer 13: 134, 2014.

13. Kurashige J, Watanabe M, Iwatsuki M, Kinoshita K, Saito S, Nagai Y, Ishimoto T, Baba Y, Mimori K and Baba H: RPN2 expression predicts response to docetaxel in oesophageal squamous cell carcinoma. Br J Cancer 107: 1233-1238, 2012.

14. Fujiwara T, Takahashi RU, Kosaka N, Nezu Y, Kawai A, Ozaki T and Ochiya T: RPN2 gene confers osteosarcoma cell malignant phenotypes and determines clinical prognosis. Mol Ther Nucleic Acids 3: e189, 2014.

15. Yuan TM, Liang RY, Chueh PJ and Chuang SM: Role of ribophorin II in the response to anticancer drugs in gastric cancer cell lines. Oncol Lett 9: 1861-1868, 2015.

16. Loo LW, Tiirikainen M, Cheng I, Lum-Jones A, Seifried A, Church JM, Gryfe R, Weisenberger DJ, Lindor NM, Gallinger S, et al: Integrated analysis of genome-wide copy number alterations and gene expression in microsatellite stable, $\mathrm{CpG}$ island methylator phenotype-negative colon cancer. Genes Chromosomes Cancer 52: 450-466, 2013.

17. Ju KD, Lim JW and Kim H: Peroxisome proliferator-activated receptor-gamma inhibits the activation of STAT3 in cerulein-stimulated pancreatic acinar cells. J Cancer Prev 22: 189-194, 2017.

18. Kim EY, Jung JY, Kim A, Chang YS and Kim SK: ABT-737 synergizes with cisplatin bypassing aberration of apoptotic pathway in non-small cell lung cancer. Neoplasia 19: 354-363, 2017.

19. Huang SN, Ruan HZ, Chen MY, Zhou G and Qian ZM: Aspirin increases ferroportin 1 expression by inhibiting hepcidin via the JAK/STAT3 pathway in interleukin 6-treated PC-12 cells. Neurosci Lett 662: 1-5, 2018.

20. Sun Y, Zhou P, Chen S, Hu C, Bai Q, Wu H, Chen Y, Zhou P, Zeng X, Liu Z, et al: The JAK/STAT3 signaling pathway mediates inhibition of host cell apoptosis by Chlamydia psittaci infection. Pathog Dis: Aug 3, 2017 (Epub ahead of print). doi: $10.1093 / \mathrm{femsle} / \mathrm{ftx} 088$.

21. Wang J, Xu J and Xing G: Lycorine inhibits the growth and metastasis of breast cancer through the blockage of STAT3 signaling pathway. Acta Biochim Biophys Sin (Shanghai) 49: 771-779, 2017.

22. Berthenet K, Bokhari A, Lagrange A, Marcion G, Boudesco C, Causse S, De Thonel A, Svrcek M, Goloudina AR, Dumont S, et al: HSP110 promotes colorectal cancer growth through STAT3 activation. Oncogene 36: 2328-2336, 2017.

23. Yan Y, Su C, Hang M, Huang H, Zhao Y, Shao X and Bu X: Recombinant Newcastle disease virus rL-RVG enhances the apoptosis and inhibits the migration of A549 lung adenocarcinoma cells via regulating alpha 7 nicotinic acetylcholine receptors in vitro. Virol J 14: 190, 2017.

24. Luo JM, Cao FL, Meng C, Lin LJ, Ma SQ, Peng SH, Gao HL, Javidiparsijani S, Wang GR, Zhang ML, et al: Clinicopathological and molecular characteristics of synchronous gastric adenocarcinoma and gastrointestinal stromal tumors. Sci Rep 7: 12890, 2017.

25. Naine SJ, Devi CS, Mohanasrinivasan V, Doss CG and Kumar DT: Binding and molecular dynamic studies of sesquiterpenes (2R-acetoxymethyl-1,3,3-trimethyl-4t-(3-methyl-2-buten-1-yl)-1tcyclohexanol) derived from marine Streptomyces sp. VITJS8 as potential anticancer agent. Appl Microbiol Biotechnol 100: 2869-2882, 2016. 
26. Li T, Ding ZL, Zheng YL and Wang W: MiR-484 promotes non-small-cell lung cancer (NSCLC) progression through inhibiting Apaf-1 associated with the suppression of apoptosis. Biomed Pharmacother 96: 153-164, 2017.

27. Taira J, Sonamoto $M$ and Uehara M: Dual biological functions of a cytoprotective effect and apoptosis induction by bioavailable marine carotenoid fucoxanthinol through modulation of the $\mathrm{Nrf} 2$ activation in RAW264.7 macrophage cells. Mar Drugs 15: E305, 2017.

28. Zhao Q, Li M, Chen M, Zhou L, Zhao L, Hu R, Yan R and Dai K: Lovastatin induces platelet apoptosis. Environ Toxicol Pharmacol 42: 69-75, 2016.

29. Hazama Y, Moriya T, Sugihara M, Sano R, Shiota M, Nakamura T and Shimoya K: The analysis of cell cycle-related proteins in ovarian clear cell carcinoma versus high-grade serous carcinoma. Int J Gynecol Pathol: Oct 10, 2017 (Epub ahead of print). doi: 10.1097/PGP.0000000000000461.

30. Wang X, Li Y, Lin M, Jin J and Huang Z: Rhodium (II) complex with 2-benzoylpyridine, a novel potential chemotherapeutic drug, induces cell cycle arrest and apoptosis in HepG2 cells. Biometals 30: 903-915, 2017.

31. He S, Liao B, Deng Y, Su C, Tuo J, Liu J, Yao S and Xu L: MiR-216b inhibits cell proliferation by targeting FOXM1 in cervical cancer cells and is associated with better prognosis. BMC Cancer 17: 673, 2017.

32. Liu L, Zhang C, Li X, Sun W, Qin S, Qin L and Wang X: miR-223 promotes colon cancer by directly targeting p120 catenin. Oncotarget 8: 63764-63779, 2017.

33. Liu H, Zhen Q and Fan Y: LncRNA GHET1 promotes esophageal squamous cell carcinoma cells proliferation and invasion via induction of EMT. Int J Biol Markers 32: e403-e408, 2017.
34. Pisamai S, Rungsipipat A, Kunnasut N and Suriyaphol G: Immunohistochemical expression profiles of cell adhesion molecules, matrix metalloproteinases and their tissue inhibitors in central and peripheral neoplastic foci of feline mammary carcinoma. J Comp Pathol 157: 150-162, 2017.

35. Ohba S, Lanigan TM and Roessler BJ: Leptin receptor JAK2/STAT3 signaling modulates expression of Frizzled receptors in articular chondrocytes. Osteoarthritis Cartilage 18: $1620-1629,2010$.

36. Li W, Zhang H, Nie M, Tian Y, Chen X, Chen C, Chen H and Liu R: Ursolic acid derivative FZU-03,010 inhibits STAT3 and induces cell cycle arrest and apoptosis in renal and breast cancer cells. Acta Biochim Biophys Sin (Shanghai) 49: 367-373, 2017.

37. Zhou W, Bi X, Gao G and Sun L: miRNA-133b and miRNA-135a induce apoptosis via the JAK2/STAT3 signaling pathway in human renal carcinoma cells. Biomed Pharmacother 84: 722-729, 2016.

38. Zhu L and Ding X: Molecular design of Stat3-derived peptide selectivity between BET proteins Brd2 and Brd4 in ovarian cancer. J Mol Recognit: Oct 6, 2017 (Epub ahead of print). doi: $10.1002 / j m r .2679$.

39. Liu X, Wei W, Li X, Shen P, Ju D, Wang Z, Zhang R, Yang F, Chen C, Cao K, et al: BMI1 and MEL18 promote colitis-associated cancer in mice via REG3B and STAT3. Gastroenterology 153: $1607-1620,2017$.

This work is licensed under a Creative Commons Attribution-NonCommercial-NoDerivatives 4.0 International (CC BY-NC-ND 4.0) License. 